\title{
Numerical Simulation Of DELAMINATION IN LAMINATED COMPOSITE Plates USING COHESIVE ELEMENTS
}

\author{
Michal Skovajsa, Frantisek Sedlacek
}
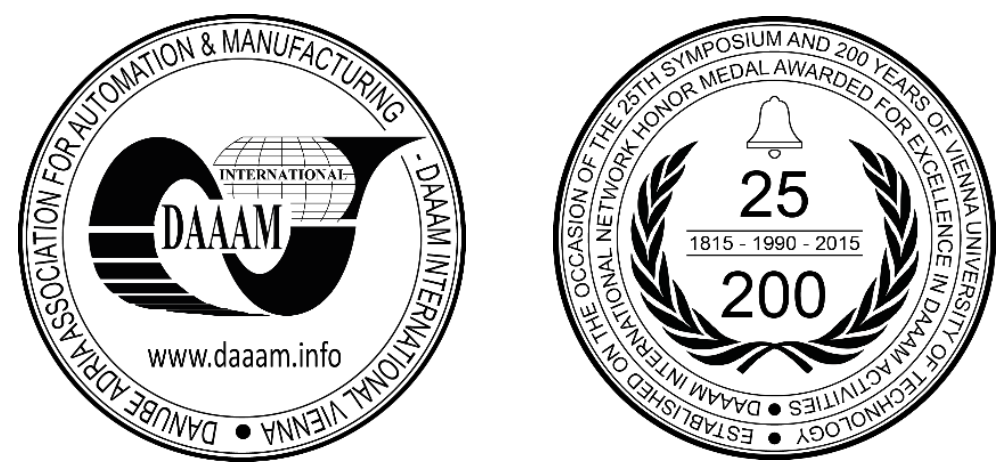

This Publication has to be referred as: Skovajsa, M[ichal] \& Sedlacek, F[rantisek] (2016). Numerical Simulation of Delamination in Laminated Composite Plates Using Cohesive Elements, Proceedings of the 27th DAAAM International Symposium, pp.0678-0685, B. Katalinic (Ed.), Published by DAAAM International, ISBN 978-3-902734-08-2, ISSN 1726-9679, Vienna, Austria

DOI: $10.2507 / 27$ th.daaam.proceedings.098

\section{Abstract}

The paper deals with the comparison of numerical simulation and analytic computation of the "Double Cantilever Beam" (DCB) test for composite materials. For numerical simulation was used the software NX Nastran 11. Comparisons are used to understand the Mode-I interlaminar fracture toughness of undirectional fibre-reinforced polymer matrix composites. The numerical simulation and analytic computation was performed according to ASTM D5528 norm. The numerical simulation was performed different size and different type of 3D fine elements.

Keywords: DCB test; composite materials; numerical simulation; analytic solution.

\section{Introduction}

Composite materials are very often used, but strength with large deformation is still problem [11]. A key factor in the design of structures from composite materials is the prediction of failure of the fibre, matrix and interlaminar delamination. There are three independent fracture modes, the crack opening mode (Mode I) is regarded as more important than the in-plane shear mode (Mode II) and out-plane shear mode (Mode III) because the Mode I fracture toughness is usually smaller than those of Mode II and Mode III and so the fracture is easily initiated and propagated under the Mode I loading condition. There is also a combination of these modes called 'Mixed-mode'. The individual modes of crack opening are shown in Figure 1.
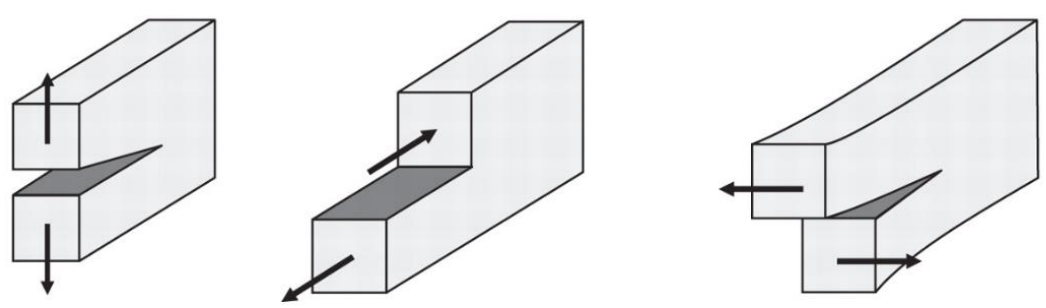

Fig. 1. - The crack opening modes (a) Mode I; (b) Mode II; (c) Mode III) 


\section{Specimen}

The dimension of the specimen was defined by standard ASTM D5528 but it does not define the exact dimensions of the specimen. The shape of the specimen is given in Figure 2. These dimensions were selected for this test. The individual dimensions of the specimen are given in Table 1.

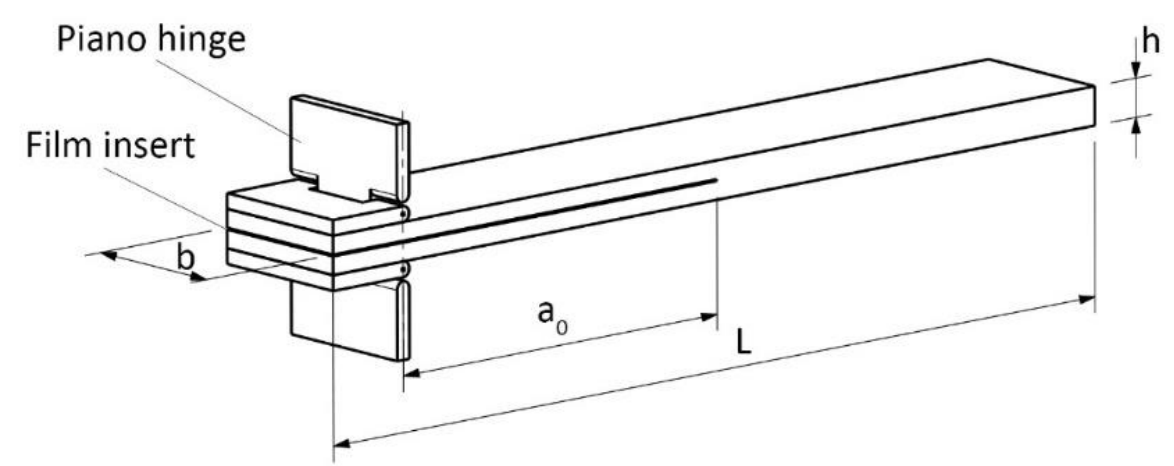

Fig. 2. Dimensions of specimen according to ASTM D5528

\begin{tabular}{|c|c|c|c|}
\hline Shortcut & Name & Norm [mm] & Selected dimensions [mm] \\
\hline L & Length of specimen & min. 125 & 130 \\
\hline $\mathrm{a}_{0}$ & Initial delamination length & approx. 50 & 50 \\
\hline $\mathrm{b}$ & Specimen width & $20-25$ & 20 \\
\hline $\mathrm{h}$ & Specimen thickness & $3-5$ & 4 \\
\hline
\end{tabular}

Table 1. Dimensions of specimen according to ASTM D5528

The ratio a/h must be greater than 10 . The ratio is 12,5 for selected dimensions. For materials with low-flexural modulus or high interlaminar fracture toughness, it may be necessary to increase the number of plies, that is, increase the laminate thickness or decrease the delamination length to avoid large deflections of the specimen arms. The specimen thickness and initial delamination length, ao, shall be designed to satisfy the following criteria: [1]

$$
\begin{aligned}
& a_{0} \leq 0,0472 \sqrt{\frac{h^{3} E_{11}}{G_{I c}}} \\
& h \geq 8,28\left(\frac{G_{I c} a_{0}^{2}}{E_{11}}\right)^{1 / 3}
\end{aligned}
$$

Where $\mathrm{a}_{0}$ is initial delamination length; $\mathrm{h}$ is specimen thickness, $\mathrm{E}_{11}$ is lamina modulus of elasticity in the fibre direction and $\mathrm{G}_{\mathrm{Ic}}-$ Critical value of the strain energy release for Mode I conditions.

Carbon reinforcement material T300/976 with the carbon fibre oriented along the length of the specimen was chosen for this specimen. The individual parameters of the material are given in Table 2. The value of the material was assumed from [2].

\begin{tabular}{|c|c|c|}
\hline Shortcut & Name & Value \\
\hline $\mathrm{E}_{11}$ & Young's Modulus, axial direction & $139.3[\mathrm{GPa}]$ \\
\hline $\mathrm{E}_{22}$ & Young's Modulus, transverse direction & $9.72[\mathrm{GPa}]$ \\
\hline $\mathrm{E}_{33}$ & Young's Modulus, normal (out-of-plane) direction & $9.72[\mathrm{GPa}]$ \\
\hline $\mathrm{G}_{12}$ & Shear Modulus, , axial direction & $5.58[\mathrm{GPa}]$ \\
\hline $\mathrm{G}_{13}$ & Shear Modulus, transverse direction & $5.58[\mathrm{GPa}]$ \\
\hline $\mathrm{G}_{23}$ & Shear Modulus, normal (out-of-plane) direction & $3.45[\mathrm{GPa}]$ \\
\hline$v$ & Poisson's Ratio in plane & $0.29[-]$ \\
\hline $\mathrm{G}_{\mathrm{Ic}}$ & Opening Mode I interlaminar fracture toughness & $0.0876[\mathrm{~N} / \mathrm{mm}]$ \\
\hline $\mathrm{C}_{\mathrm{IIc}}$ & Opening Mode II interlaminar fracture toughness & $0.3152[\mathrm{~N} / \mathrm{mm}]$ \\
\hline $\mathrm{C}_{\mathrm{IIIc}}$ & Opening Mode III interlaminar fracture toughness & $0.3152[\mathrm{~N} / \mathrm{mm}]$ \\
\hline
\end{tabular}

Table 2. Material description 


\section{Analytic computation}

The analytic solution of DCB test was calculated based on Bernoulli beam theory and linear elastic fracture mechanics $(3,4)[3,4,5]$ :

$$
\begin{aligned}
& R_{e l}=\frac{3}{2} \frac{E_{1} I}{a_{0}^{3}} \Delta \\
& R_{\text {del }}=\sqrt{\frac{3}{2} \frac{\left(b G_{I C} E_{1} I\right)^{3 / 2}}{E_{1} I \Delta}}
\end{aligned}
$$

Where $\mathrm{R}_{\mathrm{el}}$ is the linear part of the reaction force (before delamination); $\mathrm{R}_{\mathrm{del}}$ is the non-linear part of the reaction force (during delamination); $\Delta$ is the prescribed displacement; $I$ is the moment of inertia of the delaminated part; $a_{0}$ is the prescribed delamination length; $\mathrm{E}_{1}$ is Young's modulus; $\mathrm{G}_{\mathrm{Ic}}$ is the critical value of the strain energy release for Mode I conditions.

\section{Cohesive elements}

In order to model the possible inter-laminar damage, a mesoscopic approach is used, where a thin layer is inserted between two plies of the laminate (Figure 3). A specific non-linear softening law is assigned to the material of this thin layer, and its stiffness and strength can decrease and become equal to zero over the loading, simulating a de-cohesion between the plies. [8]

The approach presented in [9] is available in NX Nastran. The related constitutive polynomial softening material law for the interface is depicted in Figure 4a. Without going into the details of [9], the constitutive equation in the interface takes the following form (5), where $\mathrm{d}$ is the damage variable, identical for all the directions, and $k_{i}^{0}$ the initial stiffness:[7,8,]

$$
\left|\begin{array}{l}
\sigma_{31} \\
\sigma_{32} \\
\sigma_{33}
\end{array}\right|=\left|\begin{array}{lll}
k_{1}^{0}(1-d) & & \\
& k_{2}^{0}(1-d) & \\
& & k_{3}^{0}(1-d)
\end{array}\right| \begin{aligned}
& \gamma_{31} \\
& \gamma_{32} \\
& \gamma_{33}
\end{aligned} \mid
$$

Where $\mathrm{d}$ is equal to zero the interface is intact, while $d=1$ corresponds to inter-laminar de-cohesion. The evolution of the damage $\mathrm{d}$ for the polynomial law is given by $(6),[7,8]$.

$$
d=\left(\frac{n}{n+1} \frac{\left\langle Y-Y_{0}\right\rangle_{+}}{Y_{C}-Y_{0}}\right)^{n} \quad 0 \leq d \leq 1
$$

Where $\mathrm{Y}$ is an equivalent thermodynamic force and $\mathrm{n}, \mathrm{YC}$ are material parameters. The damage appears after a threshold Y0 defined by the user (represented by the grey regions in Figure 4). The form of the associated fracture criterion is given in $(7),[7,8]$.

$$
\left\{\left(\frac{Y_{I}}{C_{I C}}\right)^{\alpha}+\left(\frac{Y_{I I}}{C_{I I C}}\right)^{\alpha}+\left(\frac{Y_{I I I}}{C_{I I I}}\right)^{\alpha}\right\}^{1 / \alpha} \leq \frac{Y}{Y_{C}}
$$

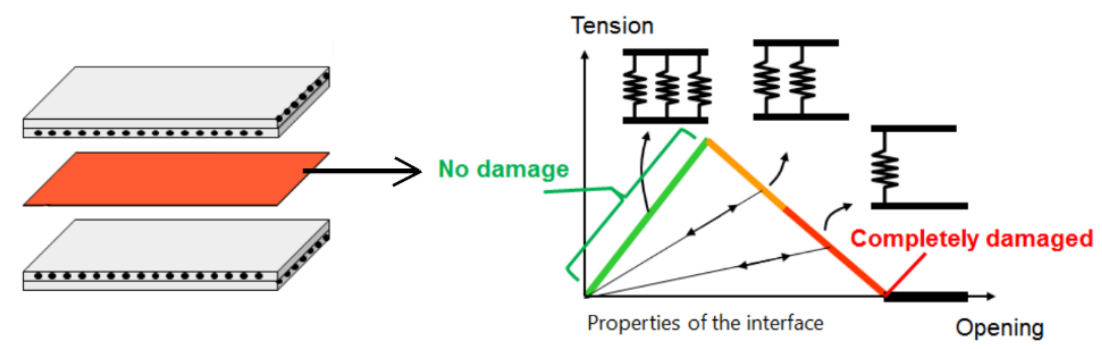

Fig. 3 Inserting an interface element between two plies of a laminate [8]

In NX Nastran, bi-triangular and exponential laws are also available [10]: they are illustrated in Figure 4. For the polynomial and bi-triangular cases, the damage appears after the threshold $\mathrm{Y}_{0}$ defined by the user. For the exponential law, the damage directly appears when the interface is loaded. $[7,8]$ 

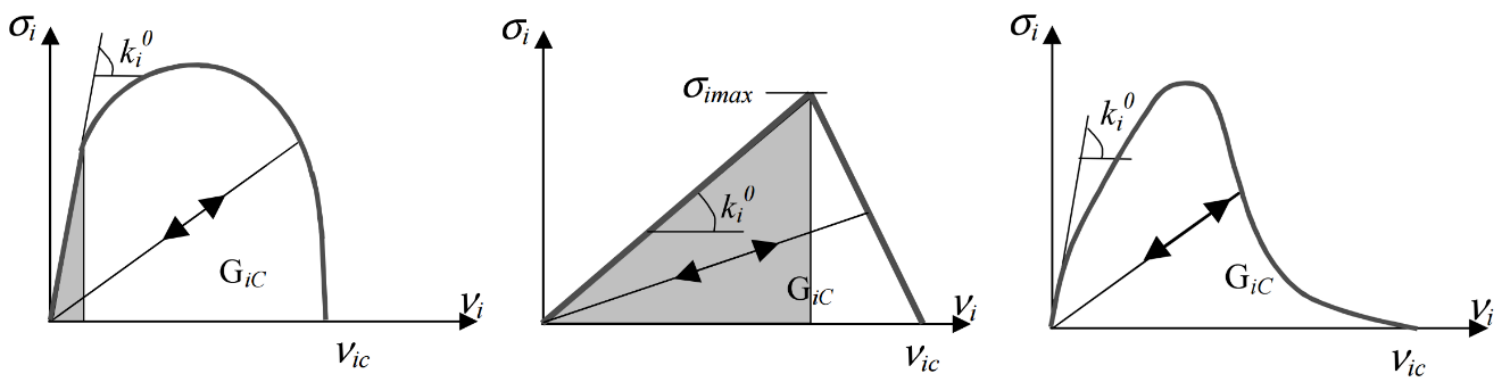

Fig. 4 The constitutive softening laws available in NX Nastran for the interface elements [8]

\section{Numerical simulation}

Numerical simulation of the DCB specimen was done using the non-linear solver NX Nastran 401. The 3D model of the specimen was created using 3D fine element mesh from linear and parabolic hexahedral elements. A cohesive layer was created between individual compounds of the DCB specimen. The bi-triangular law was used for the cohesive layer properties. The sizes $(10 \mathrm{~mm}, 5 \mathrm{~mm}, 3 \mathrm{~mm}, 2 \mathrm{~mm}, 1 \mathrm{~mm})$ of FE mesh were used for the numeric simulation. The 3D FE model with mesh and cohesive layer are given in Figure 5.

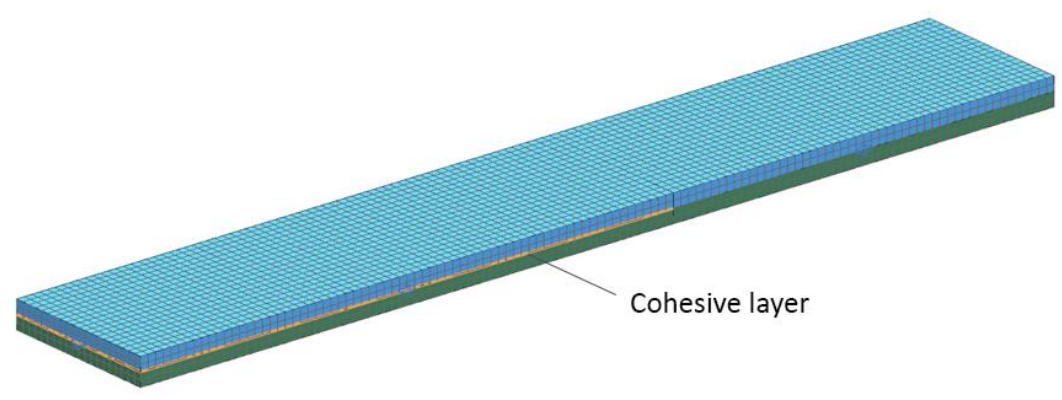

Fig. 5 3D fine element mesh model with cohesive layer

DCB Specimen was loaded by displacement on the end of the arm. The length of arms was $a_{0}$. The displacement of one arm was $2.5 \mathrm{~mm}$ with 50 steps. The two graphs below show the comparisons of all the different mesh sizes for linear and parabolic hexahedral elements. All the results are given in Figure 6.
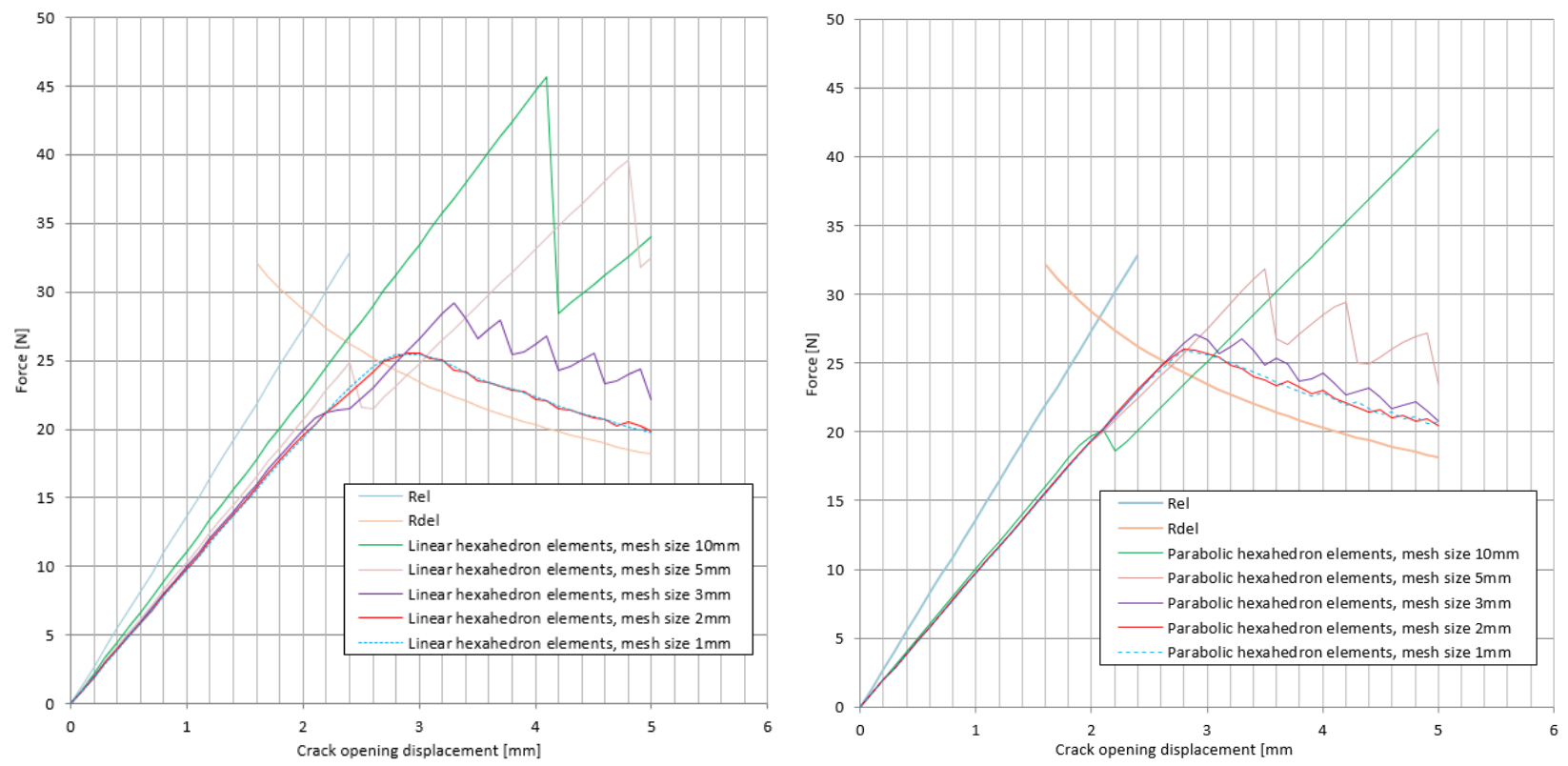

Fig. 6 Graphs with comparisons of all different sizes of mesh for linear and parabolic hexahedral elements of load displacement. 
The numerical simulations for mesh sizes $10 \mathrm{~mm}, 5 \mathrm{~mm}$ and $3 \mathrm{~mm}$ were very accurate. The simulation with the best result used linear hexahedral elements with mesh size $1 \mathrm{~mm}$. This simulation is shown in Figure $7 \mathrm{~b}$ and Figure $8 \mathrm{~b}$. The different tilt of the first linear stage was created by a different calculation of the beam model. The analytic solution according to the Bernoulli beam model does not use the orthotropic properties of the material. The Bernoulli beam model used only single elasticity modules $\mathrm{E}_{11}=\mathrm{E}_{22}=\mathrm{E}_{33}$ and the transverse shear deformation is not counted.[6] The results of the cohesive damage (BITR) are given in Figure 7a. The results of the pressure in cohesive layer are given in Figure 8a.
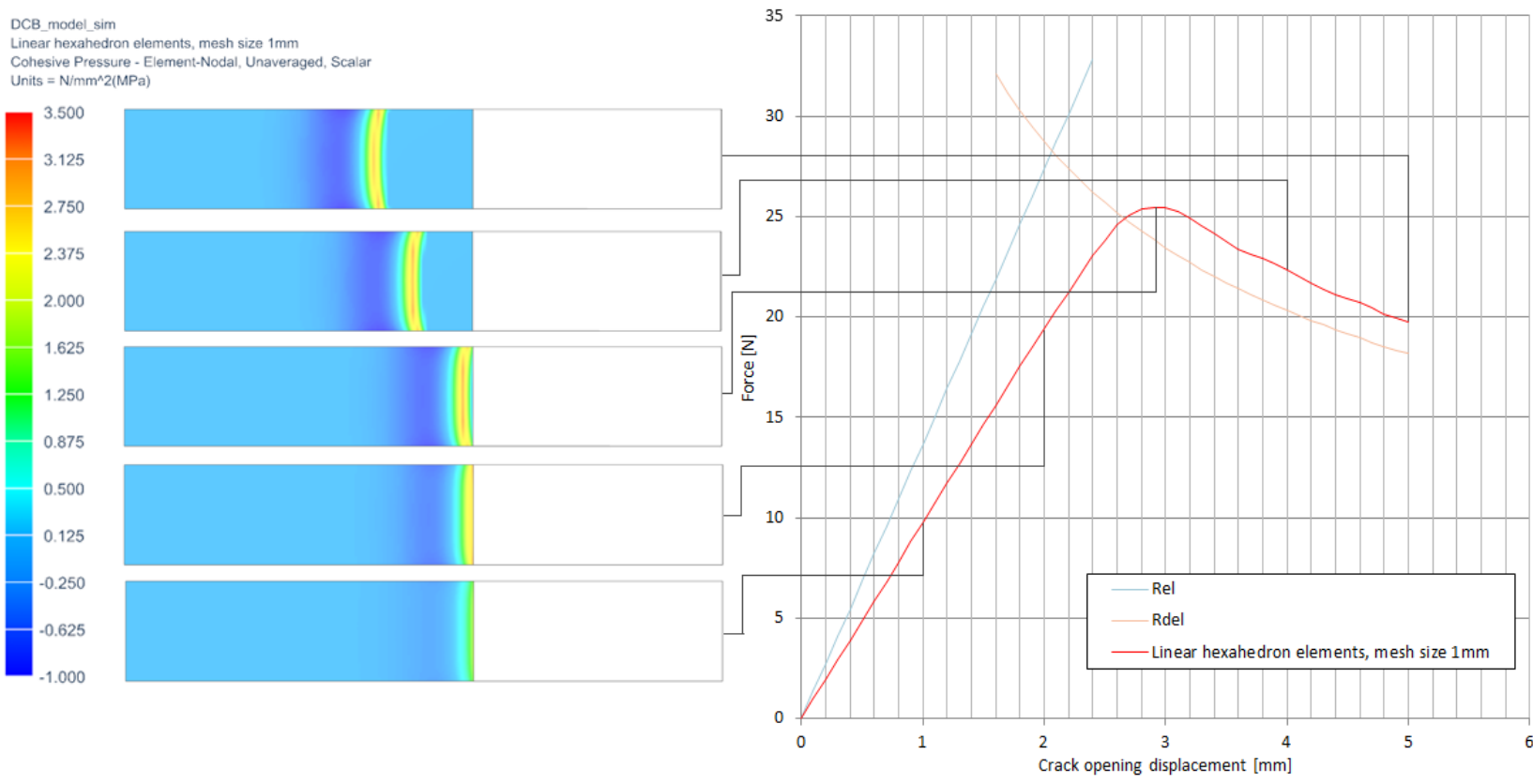

Figure 7 - (a) Results of cohesive damage (BITR); (b) load displacement trace of numerical simulation with linear hexahedral elements and with mesh size $1 \mathrm{~mm}$
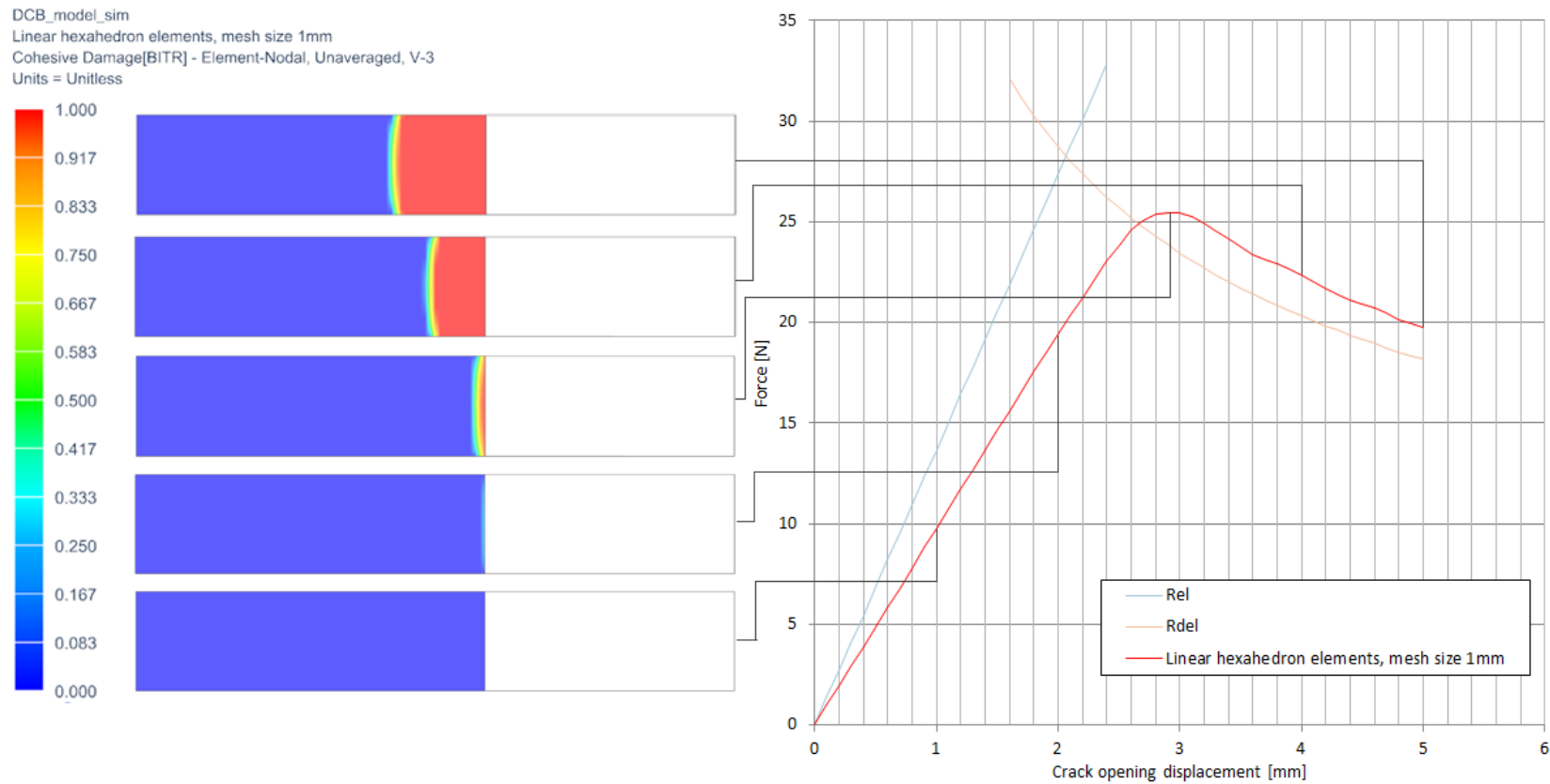

Figure 8 - (a) Results of the pressure in cohesive layer; (b) load displacement trace of numerical simulation with linear hexahedral elements and with mesh size $1 \mathrm{~mm}$

The applied load for analytic solution with crack opening displacement of $2.065 \mathrm{~mm}$ is $28.7 \mathrm{~N}$. The applied load for numerical simulation with crack opening displacement $2.9 \mathrm{~mm}$ is $25.5 \mathrm{~N}$. $11 \%$ of the applied load was the difference between the numerical and analytical results. The maximum pressure in the cohesive layer was $3.45 \mathrm{MPa}$ 
Therefore, the graph was offset by the difference of the crack opening displacement $(0.835 \mathrm{~mm})$. After offsetting the graph, the second part of the curve of the numerical simulation, which shows the damage to the cohesive layer was the same as the analytical solution. The offset result is given in Figure 9

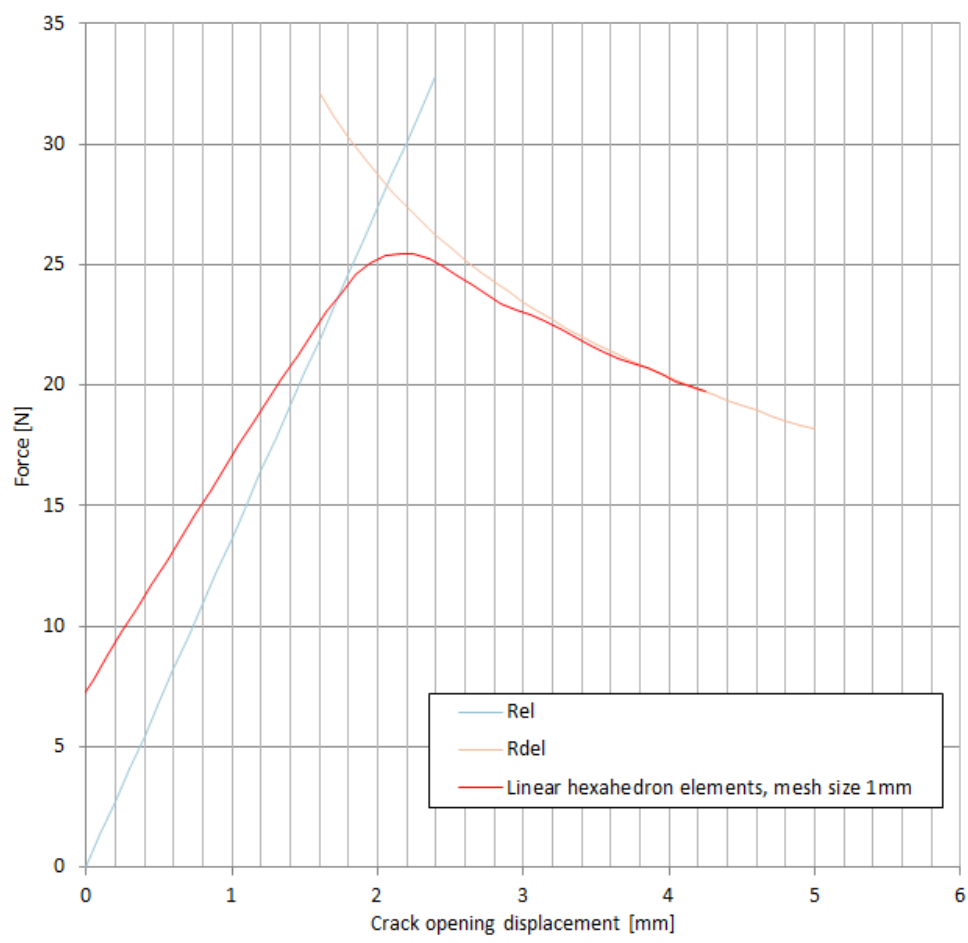

Figure 9 - Offset result of load displacement trace of numerical simulation with linear hexahedral elements and with mesh size $1 \mathrm{~mm}$

The results of the stress analysis in direction 11 are shown in Figure 10, where the shortcut COD is crack opening displacement. The maximum stress of the numerical simulation with linear hexahedral elements and with mesh size $1 \mathrm{~mm}$ was $154.46 \mathrm{MPa}$.

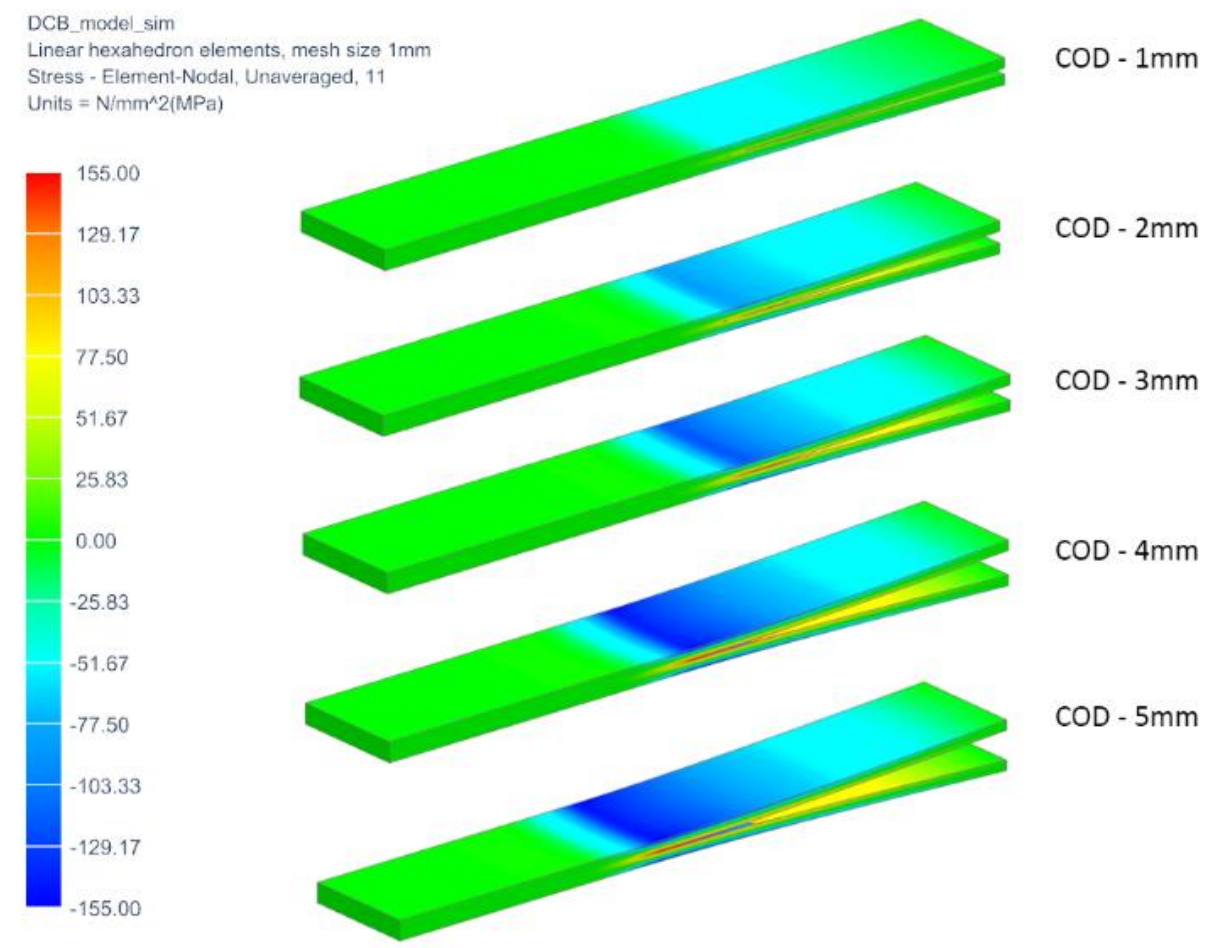

Figure 10 - The results of the stress analysis in direction 11 


\section{Comparison of the numerical simulation and the analytical solution}

The comparison of the numerical simulation with analytical solution are given in Table 3 .

\begin{tabular}{|c|l|c|c|c|}
\hline $\begin{array}{c}\text { Number of } \\
\text { simulation }\end{array}$ & 3D FE & $\begin{array}{c}\text { Applied } \\
\text { maximum } \\
\text { load [N] }\end{array}$ & $\begin{array}{c}\text { Shape of } \\
\text { applied load } \\
\text { curve }\end{array}$ & $\begin{array}{c}\text { Comparison } \\
\text { with analytic } \\
\text { solution }\end{array}$ \\
\hline 1 & Linear hexahedron elements, mesh size $10 \mathrm{~mm}$ & 45.7 & Very Inaccurate & $159,5 \%$ \\
\hline 2 & Linear hexahedron elements, mesh size $5 \mathrm{~mm}$ & 39.6 & Very Inaccurate & $138,2 \%$ \\
\hline 3 & Linear hexahedron elements, mesh size $3 \mathrm{~mm}$ & 29.2 & Inaccurate & $101,9 \%$ \\
\hline 4 & Linear hexahedron elements, mesh size $2 \mathrm{~mm}$ & 25.4 & Accurate & $88,7 \%$ \\
\hline 5 & Linear hexahedron elements, mesh size $1 \mathrm{~mm}$ & 25.5 & Very accurate & $89,0 \%$ \\
\hline 6 & Parabolic hexahedron elements, mesh size $10 \mathrm{~mm}$ & unfailure & Incomparable & \\
\hline 7 & Parabolic hexahedron elements, mesh size $5 \mathrm{~mm}$ & 31.8 & Very Inaccurate & $111,0 \%$ \\
\hline 8 & Parabolic hexahedron elements, mesh size $3 \mathrm{~mm}$ & 27.1 & Inaccurate & $94,6 \%$ \\
\hline 9 & Parabolic hexahedron elements, mesh size $2 \mathrm{~mm}$ & 26 & Accurate & $90,8 \%$ \\
\hline 10 & Parabolic hexahedron elements, mesh size $1 \mathrm{~mm}$ & 26 & Very accurate & $90,8 \%$ \\
\hline
\end{tabular}

Table 3 - Comparison of the numerical simulation and analytical solution

The result with minimum difference of applied load between the numerical simulation and the analytical solution was achieved with result number 3 , but the shape of this result curve is very inaccurate and has great amplitude. In this case the best result is number 5 , where the shape of the result curve is very similar to the analytical solution

\section{Conclusion}

This paper deals with the comparison of numerical simulation and analytical computation according to Bernoulli beam theory. The question was: Which type of 3D fine elements is suitable to use for numerical simulation with new non-linear solver NX Nastran 401 in NX Nastran 11. The norm ASTM D 5528 was used to define the specimen dimensions. Linear and parabolic hexahedral elements with different mesh sizes were used for the numerical simulation. A cohesive layer was created between individual components of the DCB specimen. The best result of the numerical solution was achieved using linear hexahedral elements with mesh size $1 \mathrm{~mm}$.

The stiffness of the specimen was smaller when using the numerical simulation than with the analytical solution, because the analytical solutions only used single elasticity modules. The result with the minimum difference of applied load between the numerical simulation and analytical solution was result number 3, but the shape of this result curve was very inaccurate and has a great amplitude. In this case the best result is result number 5, where the shape of the result curve is very similar to the analytical solution.

The applied maximum load using numerical simulation with result number 5 (Table 3) was smaller than the analytical solution by about $11 \%$. The applied maximum load using the numerical simulation was $25.5 \mathrm{~N}$. For numerical simulation of interlaminar fracture in Mode I should be used the linear hexahedron elements with mesh size $1 \mathrm{~mm}$ or $2 \mathrm{~mm}$. These elements provide sufficiently accurate results.

We are currently working on manufacturing a specimen for DCB for experimental testing and verification of the numerical simulations to best-fit the numerical simulation to a realistic value.

\section{Acknowledgements}

This paper is based on work sponsored by project SGS2016-012 (The complex support of designing of technical equipment III.).

\section{References}

[1] Standard Test Method for Mode I Interlaminar Fracture Toughness of Unidirectional Fiber-Reinforced Polymer Matrix Composites, Designation: D 5528 - 01 (Reapproved 2007)

[2] Hosseini-Toudeshky H, Hosseini S, Mohammadi B. Delamination buckling growth in laminated composites using layerwise-interface element. Compos Struct 2010;92(8):1846-56.

[3] Tenchev RT, Falzon BG. A pseudo-transient solution strategy for the analysis of delamination by means of interface elements. Finite Elem Anal Des 2006;42(8-9):698-708. 
[4] Mi Y, Crisfield MA, Davies GAO. Progressive delamination using interface elements. J Compos Mater 1998;32(14):1246-72.

[5] Szekrényes A. Interlaminar stresses and energy release rates in delaminated orthotropic composite plates. Int J Solids Struct 2012;49(18):2460-70.

[6] Miroslav Marjanovic, Günther Meschke, Djordje Vuksanovic, A finite element model for propagating delamination in laminated composite plates based on the Virtual Crack Closure method., 2016

[7] m. Bruyneel , J.P. Delsemme , A.C. Goupil , P. Jetteur , C. Lequesne , T. Naito And Y. Urushiyama Damage modeling of laminated composites: validation of the inter-laminar damage model of samcef at the coupon level for ud plies

[8] M. Bruyneel1 , J.P. Delsemme1, P. Jetteur1 and F. Germain, A study of complex delaminations in laminated composite structures with SAMCEF, University of Liège, Belgium, 26-28 May 2008

[9] P. Ladevèze, O. Allix, B. Douchin and D. Lévêque. A computational method for damage intensity prediction in a laminated composite structure, Computational Mechanics - New Trends and Applications (Idelsohn S., Oñate E. and Dvorkin E., eds.), CIMNE, Barcelona, Spain, 1998.

[10] P. Jetteur. Model material for the interface element Report RS-246. 2006.

[11] Sedlacek, F.; Lasova, V. \& Kottner, R.: Design of Flexible Composite Bellows Coupling, Proceedings of the 26th DAAAM International Symposium, pp.0930-0935, Published by DAAAM International, ISBN 978-3-902734-075, ISSN 1726-9679, Vienna, Austria 